\title{
The Proposed EU Digital Services Regulation 2020:
}

\author{
Data Desiderata
}




\title{
The Proposed EU Digital Services Regulation 2020: \\ Data Desiderata
}

\author{
Peter Georg Picht* / Heiko Richter ${ }^{* *}$
}

\begin{abstract}
With the drafts of the Digital Markets Act (DMA), the Digital Services Act (DSA), and the Data Governance Act (DGA), the EU Commission has presented three cornerstones of its digital regulation approach in November and December of 2020. This Discussion Paper looks at data transactions and focuses on four aspects which illustrate that the proposed Acts leave much room for advancing the coherence and specificity of its respective rules: the specificity of data-related provisions; the role of FRAND in the package context; the role of data intermediaries; and the upcoming Data Act. Beyond diagnosis, the Discussion Paper calls for a more integrative approach and proposes improvements. It aims to spark a more intense discourse on data transactions under the Package.
\end{abstract}

Keywords: Digital Markets Act, Digital Services Act, Data Governance Act, Competition, Data Regulation, Data Act, FRAND, Data Trustees, Data Intermediaries

\footnotetext{
* Prof. Dr. Peter Georg Picht, LL.M. (Yale), holds a chair for economic law at Zurich University, heads the University's Center for Intellectual Property and Competition Law, and is an Affiliated Research Fellow with the Max Planck Institute for Innovation and Competition in Munich.

${ }^{* *}$ Dr. Heiko Richter, LL.M. (Columbia), is Senior Research Fellow at the Max Planck Institute for Innovation and Competition in Munich.
} 


\section{Scope of the Discussion Paper}

With the drafts of the Digital Markets Act (DMA), ${ }^{1}$ the Digital Services Act (DSA), ${ }^{2}$ and the Data Governance Act (DGA), ${ }^{3}$ the EU Commission has recently presented three cornerstones of its digital regulation approach (together hereinafter the "Package"). Focusing, so far, on the DMA, the discourse assessing the drafts has, rightly, pointed out that the proposed provisions lack in specificity and flexibility at the same time. ${ }^{4}$ While their wording is, in many respects, so imprecise as to hamper applicability even to clearly discernible settings, adjustability to sectoral particularities ${ }^{5}$ or future market developments does not seem evident either. Furthermore, even the interplay of regulatory elements within the DMA forebodes inconsistencies and inefficiencies, as critics have pointed out regarding the relationship between Articles 5, 6 and 7(2) DMA. ${ }^{6}$

Building on these insights, this Discussion Paper looks at data transactions under the DMA, taking into consideration also the impact of the DGA. As it cannot exhaust this rich topic, the Paper focuses on four aspects which illustrate that the Package, in its present form, leaves much room for advancing the coherence and specificity of its rules on data transactions. These aspects are the specificity of data-related

${ }^{1}$ COM(2020) 842 final, Proposal for a Regulation of the European Parliament and of the Council on contestable and fair markets in the digital sector (Digital Markets Act). ${ }^{2} \mathrm{COM}(2020) 825$ final, Proposal for a Regulation of the European Parliament and of the Council on a Single Market For Digital Services (Digital Services Act) and amending Directive 2000/31/EC.

${ }^{3} \mathrm{COM}(2020) 767$ final, Proposal for a Regulation of the European Parliament and of the Council on European data governance (Data Governance Act).

${ }^{4}$ Cf. e.g. Luís Cabral et al., The EU Digital Markets Act: A Report from a Panel of Economic Experts, 2021, JRC122910, available at https://ssrn.com/abstract=3783436, p. 2; Jürgen Basedow, Das Rad neu erfunden: Zum Vorschlag für einen Digital Markets Act (Reinventing the Wheel: The Proposal for a Digital Markets Act), Max Planck Private Law Research Paper No. 21/2, available at https://ssrn.com/abstract=3773711, p. 3, published in 29 Zeitschrift für Europäisches Privatrecht 2021, 217; Heike Schweitzer, The Art to Make Gatekeeper Positions Contestable and the Challenge to Know What is Fair: A Discussion of the Digital Markets Act Proposal (April 30, 2021), available at https://ssrn.com/abstract=3837341, p. 29, published in 29 Zeitschrift für Europäisches Privatrecht 2021, 503; Daniel Zimmer and Jan-Frederick Göhsl, Vom New Competition Tool zum Digital Markets Act: Die geplante EU-Regulierung für digitale Gatekeeper, 19 Zeitschrift für Wettbewerbsrecht 2021, 29 (44, 53 ff.); Alexandre de Streel, Richard Feasey, Jan Kraemer, and Giorgio Monti, Making the Digital Markets Act More Resilient and Effective (May 26, 2021), available at https://ssrn.com/abstract=3853991, p. 88 ff. Cf. also Wolfgang Kerber, Taming Tech Giants with a Per-Se Rules Approach? The Digital Markets Act from the "Rules vs. Standard" Perspective (June 7, 2021), available at https://ssrn.com/abstract=3861706, for the underlying theory of regulatory choice and trade-offs when making this choice.

5 This point has been illustrated by Cristina Caffarra and Fiona Scott Morton, The European Commission Digital Markets Act: A translation (5 Jan 2021) https://voxeu.org/article/european-commission-digital-markets-act-translation (accessed 8 Sep 2021).

${ }^{6}$ Discussed in detail by de Streel/Feasey/Kraemer/Monti (supra 4). 
provisions (II.), the role of FRAND in the package context (III.), the role of data intermediaries (IV.), and the upcoming Data Act (V.). Beyond diagnosis, the Paper proposes improvements, also in the hope to spark a more intense discourse on data transactions under the Package.

\section{Lack of Specification of Data-Related Provisions}

1. The DMA sets out various data-/information-related provisions. ${ }^{7}$ On the one hand, it contains provisions which aim to foster competition and innovation by obliging Gatekeepers to provide information or datasets. ${ }^{8}$ On the other hand, it contains prohibitions for Gatekeepers to combine certain data (Art. 5(a)) and to make particular uses of data generated by competing business users' activities (Art. 6(1)(a)). From a bird's eye view, the DMA currently assembles a mingle-mangle of data-related obligations which address various regulatory goals and are of very limited sensitivity to differing market contexts and industries. Not least for this reason, a balance between adequate regulatory flexibility on the one hand and the necessary further, targeted specification is key for effectively implementing these obligations. ${ }^{9}$

2. The package leaves open many relevant questions in need for further specification. On the "enabling side", this concerns crucial procedural and technical requirements for formats and interfaces for data transfer (e.g. design and functionality of the interface ${ }^{10}$ and data format), the concerned data (aggregated, non-aggregated), and modalities for data transfers. The DMA is also silent on the concrete measures for enabling data portability, which the EU legislator appears to largely shift to the upcoming draft of the Data Act. ${ }^{11}$ On the "prohibiting side", a key question concerns the technological requirements actors have to implement to comply with their duties (as e.g. the duty of Gatekeepers to "refrain from using" provided data under

\footnotetext{
${ }^{7}$ Cf. in detail Simonetta Vezzoso, The dawn of pro-competition data regulation for gatekeepers in the EU, 17 European Competition Journal 2021, 391.

${ }^{8}$ In particular: Art. 5(g) obligation to provide advertisers and publishers information upon request; Art. 6(1)(g) obligation to provide advertisers and publishers measuring tools and information for verification upon request; Art. 6(1)(h) obligation to provide portability; Art. 6(1)(i) obligation to provide real-time access to data generated in context of use of Gatekeepers; Art. 6(j) obligation to provide data to online search engines upon request

${ }^{9}$ Cf. Kerber (supra 4), p. 3 ff., on the underlying theory of economic trade-offs.

${ }^{10}$ E.g. Open APIs as proposed by de Streel/Feasey/Kraemer/Monti (supra 4), p. 54.

${ }^{11}$ See Inception impact assessment, Ares(2021)3527151, p. 3, which rightly identifies the weakness of DMA, which wouldn't "provide any description of what 'enabling portability' means in this context, nor which terms should apply while enabling portability" and offers that "codes of conduct could offer a suitable tool for providers to show their compliance".
} 
Art. 6(1)(a) DMA or the obligation of data intermediaries to implement sufficient security measures as required by Art. 11 DGA).

3. It goes beyond this Paper to discuss these questions in detail. ${ }^{12}$ However, the Paper wishes to address the overarching issue of a suitable regulatory approach and procedure for specification. This question is delicate because the way the regulator governs these issues not only affects the degree of competition and innovation, but it impacts society and welfare at large (e.g. data security, the outflow of data to non-democratic jurisdictions, etc.). Therefore, the issue which factors are to be left to determination by free market forces requires particular caution. At the same time, many data-related behavioral requirements need to be specified in advance and controlled ex post. It appears hardly possible to regulate and monitor everything via a central instance, such as the Commission (on private enforcement cf. 16.4.).

4. Taking these caveats into account, the following three adjustments may improve the DMA's balance between flexibility and specification.

4.1. The specification of measures by Commission decision (Art. 7(2) DMA) is the main instrument of the regulator to specify datarelated obligations under Art. 6 DMA.

4.1.1. Commentators have rightly questioned the conceptual differentiation between Art. 5 and 6 DMA and concluded that there is no substantial reason to limit the application of specifying decisions only to obligations under Art. 6 DMA. ${ }^{13}$ Rather, obligations under Art. 5 DMA may equally pose the need for further specification. We therefore support the claim that Art. 7(2) DMA should also include obligations under Art. 5 DMA, at least the data-related ones.

4.1.2. Depending on the case at hand, the period of 6 months after specification (Art. 7(2) DMA) has been criticized as being too short for defining and imposing concrete data sharing obligations, so that more flexibility for the Commission may be needed here. ${ }^{14}$

4.1.3. In general, we take a critical view of too strong a focus on a "regulatory dialogue" 15 that, limiting itself to individual cases, runs the risk of overlooking broader dynamic effects on related markets, valid concerns and interests of third parties, as well as the common good. Decisions under Art. 7(2) DMA may e.g. lead to technical de facto standards without taking into consideration the views of market players

\footnotetext{
${ }^{12}$ But see de Streel/Feasey/Kraemer/Monti (supra 4), p. 41 ff.; Cabral et al. (supra 4), p. $11 \mathrm{ff}$.

${ }^{13}$ Cf. Schweitzer (supra 4), p. $25 \mathrm{ff}$.

14 Cf. de Streel/Feasey/Kraemer/Monti (supra 4), pp. 29, 64. questioning the proportionality and discussing the flexibility for the Commission to specify the deadline.

${ }^{15}$ Cf. Vezzoso (supra 7), 400.
} 
that do not participate in the respective regulatory dialogue but will have to live with said standard. To move the DMA closer to responsive and holistic regulation (rather than leading to a rag rug of various decisions which evoke arbitrary effects), it should provide for an inclusive bottom-up approach which is targeted to the relevant stakeholders and conducted with an overarching view on a variety of actual and potential cases. This means that the DMA should offer a more structured approach for specification, which would systematically involve all stakeholders whose interests are affected by the decisions. This does not only concern Gatekeepers and recipients of data (not least because recipients may have to implement specific technical measures or make security commitments before a data transfer is possible), ${ }^{16}$ but also independent data intermediaries ${ }^{17}$ as well as representatives of data subjects (consumers).

\subsection{The DMA contains an "in-built provision for}

specification": Art. 36 DMA empowers the Commission to enact implementing acts concerning "the form, content and other details of technical measures that Gatekeepers shall implement in order to ensure compliance with points (h), (i) and (j) of Article 6(1)". Indeed, such implementing acts can provide some legal and economic certainty ex ante. However, with a view to the bottom-up approach proposed heretofore, Art. 36 DMA should be modified as follows:

4.2.1. Art. 36 should be extended to include the power of the Commission to adopt implementing acts with regard to Art. 5(g), Art. 6(1)(g) as well as Art. 5(a) and Art. 6(1)(a) DMA. In all these cases, an ex-ante specification appears desirable.

4.2.2. Moreover, the Commission should rely on a targeted, overarching bottom-up process when drafting the respective implementing acts. Their preparation traditionally involves constructive stakeholder participation only to a certain extent and not necessarily in a very structured manner. ${ }^{18}$ The DMA should specify a procedure ensuring that the peculiarities of the affected industries and markets are considered and that interests of affected stakeholders are addressed more systematically. For this purpose, Art. 36 DMA should borrow from Art. 14 of the PSI and Open Data Directive, ${ }^{19}$ which defines substantive criteria (e.g. for the selected datasets, general principles for formats and data transfer, and particular interests to be taken into account) as well as additional procedural requirements (e.g. expert and stakeholder involvement in the mandatory assessment) for enacting an implementing act on high value datasets.

\footnotetext{
${ }^{16}$ Cf. de Streel/Feasey/Kraemer/Monti (supra 4), p. 29.

${ }^{17}$ See part III. on their significance.

${ }^{18}$ For details see SWD(2017) 350, Better Regulation Guidelines.

${ }^{19}$ Directive (EU) 2019/1024 of the European Parliament and of the Council of 20 June 2019 on open data and the re-use of public sector information, OJ L 172, 26.6.2019.
} 
4.3. Providing more flexibilities for decisions under Art. 7 DMA while extending and specifying Art. 36 DMA should be accompanied by a sequenced "implementation plan" for the DMA. This plan could prioritize legislative actions, define and clearly communicate milestones to be reached in a broader stakeholder dialogue, and sync both - especially at an early implementation stage - with companyspecific regulatory dialogues (Art. 7 DMA) and market investigations (Art. 16 DMA).

\section{FRAND in the Package Context}

5. A number of references to FRAND (Fair, Reasonable And NonDiscriminatory) in the Package demonstrates that the regulator perceives this concept as an important cornerstone for various transactional settings governed by the Acts. For instance:

5.1. Pursuant to Art. 6(1)(j) and Recital (56) DMA, Gatekeepers shall grant to online search engine providers "access on fair, reasonable and non-discriminatory terms to ranking, query, click and view data in relation to free and paid search generated by end users on online search engines of the gatekeeper".

5.2. Art. 6(1)(d) DMA obliges Gatekeepers to "apply fair and non-discriminatory conditions" in its ranking services.

5.3. Art. 6(1)(k) DMA requests the application of "fair and nondiscriminatory general conditions of access for business users" to app stores.

5.4. Pursuant to Art. 11(3) DGA, a provider of data sharing services "shall ensure that the procedure for access to its service is fair, transparent and non-discriminatory for both data holders and data users, including as regards prices".

6. Beyond the present draft Acts of the Package, the upcoming Data Act (cf. also below, V.) aims for "data access and use rights, potentially on the basis of fair, reasonable, proportionate, transparent and nondiscriminatory terms for non-personal data". ${ }^{20}$

7. However, these and further provisions do nothing to flesh out what FRAND really means under the Package. In principle, the FRAND concept has much potential for reconciling contradicting interests related to the access to a valuable (intangible) resource. Experiences in the concept's root area of standard-essential patent (SEP) licensing show, though, that it is no sure-fire success. On the contrary, SEPFRAND-licensing is haunted by hold-up, excessive global litigation, and at times rather inefficient deal-making. The application of FRAND

${ }^{20}$ Inception impact assessment, Ares(2021)3527151, p. 5. 
under the Package must therefore try to avoid shortcomings of SEPFRAND-licensing. The balance of this section suggests a few illustrative aspects in this respect.

8. Regarding FRAND content requirements, it is paramount to realize that the concept cannot work as a one size fits all solution but that it must be adjusted to the respective type of transaction. FRAND ranking conditions (Art. 6(1)(d) DMA) and FRAND data access conditions, for instance, will look very different and it would be illusory to hope that a catch-all reference to FRAND suffices to order so heterogeneous a range of transactions.

8.1. Where the transaction at issue is about access to data portfolios, it can regularly be conceptualized as a sort of license, albeit an atypical one.

8.2. While not necessarily preventing market mechanisms from shaping the conditions of such licenses, the Package regulation should mitigate far-reaching uncertainty over what these conditions could look like, an uncertainty market participants may need a long time to reduce. Instead, it should employ a procedural approach (cf. 11.) to develop sets of model conditions for prototypical data access transactions, including data pricing approaches.

9. Regarding FRAND conduct requirements, best practice-guidance on how transaction parties ought to behave, developed early after the enactment of the Package, could mitigate the protracted court fights over the (un)FRANDliness of party conduct we see in the SEP-FRAND arena. As there is relatively little market experience in complex data access transactions at all, and none regarding transactions under the Package Acts, conduct elements like the timeliness of parties' reactions, the information with which they have to substantiate their requests, the legitimacy of invoking confidentiality protection (including for thirdparty (personal) data), or the permissibility of multi-forum litigation (including multiple layer-antisuit injunctions) risk otherwise to provide much substance for legal warfare.

10. FRAND-based rights to access and use data under the Package should be acknowledged as both a claim and a defense which can be raised in legal proceedings.

11. Not least due to the novelty of data access transactions (under the Package Acts), FRAND-supportive institutional structures should be a focus of attention for the regulator. Developing prototypical condition sets for access transactions, conduct guidance for the parties engaging in such transactions, and alternative dispute resolution mechanisms, as for instance specialized arbitration panels, count among early worthwhile tasks for such institutions. 
11.1. The regulatory dialogue, envisaged mainly by Art. 7 DMA to specify Gatekeepers' obligations under Art. 6 DMA, can be an element helpful in furthering FRAND. However, said dialogue is of a more bilateral, case-by-case nature and, therefore, better suited to implement than to develop overarching FRAND guidance.

11.2. Lack of resources and sector-specific experience but also fundamental concerns over state interventionism mean that Member States or the EU Commission are in no position to - early on and unilaterally - decree details of FRAND under the Package. Stakeholders, representing the key interests and groups involved, should instead play the crucial role, both in the conceptualization of general FRAND guidance and in specific regulatory dialogues on FRAND.

11.3. Data intermediaries, in particular, can drive the process of making FRAND work in practice (cf. IV.). Based on their market involvement, data intermediaries are apt to help defining FRAND content and conduct, as well as to implement such guidance in data transactions (e.g. FRAND access claims by data pools they manage). ${ }^{21}$ At the same time, assigning data intermediaries an important role in realizing FRAND under the package will likely increase their relevance and market success, thereby contributing to the purposes of the DGA.

12. As to the appropriate legislative structure for implementing the aforementioned elements, the Acts of the Package cannot themselves address content, conduct and structural aspects at a very detailed, sector- and context-specific level. For this, they should refer to one or several supplementary pieces of state legislation. For instance, in case the EU Commission carries out the plan of issuing FRAND-specific regulation, ${ }^{22}$ its focus is likely to be on the SEP context. Nonetheless, such regulation should make allowance for first experiences with FRAND under the Package (if already existing) and possibly address the Package context as well. Stakeholder self-regulation or soft law are further options in lieu of mandatory state law. The swifter and more effective market participants adopt such self-regulation and/or soft law, the less extensive supplementary state legislation needs to become. A future Data Act (cf. 17.) should be aligned with this legislative concept.

\footnotetext{
${ }^{21}$ See also the EU Commission's position that, in the framework of B2G data sharing under a future Data Act, intermediate structures could be mandated to "facilitate agreement on the conditions of use of such data, including remuneration", Inception impact assessment, Ares(2021)3527151, p. 5.

$22 \mathrm{Cf}$. the corresponding announcement in the Inception impact assessment, Ares(2021)3527151.
} 


\section{Strengthen the Role of Data Intermediaries}

13. The legislator should further strengthen the role of data intermediaries and develop it, where appropriate, towards a role of Data Intermediary Trustees. While not necessarily being nonprofit entities, such Trustees could carry out market interactions with a view to safeguarding the interests of (groups of) market participants the Package wishes to protect, as well as the common good. While the DGA at least aims to foster data intermediaries, the other proposed Acts fail to properly address their potential. The Acts' differing rules on procedure and competencies aggravate this lack of substance and coherence as they tend to prevent data intermediaries from efficiently operating across the settings covered by the Package.

14. In the interest of legal certainty and the correct assessment of regulatory effects, the DMA and the DGA should clarify and delineate their respective scopes regarding data sharing services and data intermediaries. This could be implemented by including a new Art. 1(3) DGA and a new Art. 1(6)(a) DMA.

14.1. The DGA is imprecise regarding its own scope of application. ${ }^{23}$ While its Recital (22) provides some descriptive language and examples, the Act's articles fail to offer a general definition and categorization of data sharing service providers and data intermediaries. The present state of blur risks to lead to adverse consequences, as the subsequent paragraphs show.

14.2. Recital (22) DGA exempts from its scope of application cloud computing en bloc, even though some of its functionalities are clearly data sharing services in the sense of the Act. As a result, cloud computing providers which do not qualify as Gatekeepers under the DMA profit from a regulatory loophole, and even Gatekeeper cloud computing providers ${ }^{24}$ are regulated merely by the DMA, unjustifiably escaping stricter ${ }^{25}$ obligations under the DGA and profiting from an unlevel playing field in comparison with smaller data sharing service providers that do not also offer cloud computing. The DGA should therefore not generally exempt cloud computing providers.

14.3. Moreover, Recital (22) DGA vaguely refers to the "main objective" of providers as the decisive point of reference for applying

\footnotetext{
${ }^{23}$ For details, cf. Heiko Richter, Europäisches Datenprivatrecht: Lehren aus dem Kommissionsvorschlag für eine „Verordnung über europäische Daten-Governance“, 29 Zeitschrift für Europäisches Privatrecht 2021, 634 (649 ff.).

${ }^{24}$ They form by no means a merely theoretical category as AWS and MS AZURE are expected to be covered by the DMA, see Caffarra/Scott Morton (supra 5).

${ }^{25}$ Cf. Inge Graef and Raphael Gellert, The European Commission's proposed Data Governance Act: some initial reflections on the increasingly complex EU regulatory puzzle of stimulating data sharing (March 25, 2021), TILEC Discussion Paper No. DP2021-006, available at https://ssrn.com/abstract=3814721, p. 12.
} 
the DGA. Especially for large companies, this creates the chance to offer data sharing services as a side-business, free of DGA regulation. To plug such loopholes, the DGA should link its application to the actual provision of a data sharing service, even if such application remains limited to a (material) part of a company's business. ${ }^{26}$ As one consequence, the data sharing service activities of Gatekeepers (which may also constitute core platform services in the sense of Art. 2(2) DMA) would be subject to the structural separation and restriction of use obligations under Art. 11(1) DGA, irrespective of how central they are to the Gatekeeper's overall business model. At the same time, the Commission should reconsider the limitations on services - as reflected in Recital (22) DGA (no group-specific, cloud-related, holder-to-userlicensing, or (copyrighted) content intermediating services) - a DGA data intermediary may offer, especially where such intermediary would perform the role of a Data Intermediary Trustee.

14.4. Since Gatekeepers addressed by the DMA can, at the same time, qualify as DGA data sharing service providers and since Recital (22) DGA carves out only certain types of Gatekeepers, the scopes of DMA and DGA respectively are less mutually exclusive than they may at first appear. Hence, the Acts need to answer more clearly the question of whether Gatekeepers should be entitled to act as DGA data intermediaries. Completely prohibiting such a combined status seems unwarranted since Gatekeepers may need to perform data sharing activities as an integral part of their business models and since they are likely innovation drivers for such activities as well. Regarding some data intermediation activities, however, the systemic potential for conflicts of interest, for harm to data subjects or data recipients, and for a further strengthening of Gatekeepers' market power suggest a prohibition for Gatekeepers to exercise such activities. Hence, the DGA $^{27}$ should prohibit DMA Gatekeepers from providing Data Intermediary Trustee services in the sense of Art. 9(1) lit. b and c DGA. As to other DGA data sharing services, additional limitations should apply where they are provided by DMA Gatekeepers or players with substantial market power. For instance, Art. 11 DGA should explicitly prohibit such players to - contractually, economically, or otherwise - tie/bundle DGA data intermediary services with other business activities. Confining, thus, the carrying out of data intermediary business by Gatekeepers also promises, as a welcome side-effect, to support burgeoning market success of smaller data

\footnotetext{
${ }^{26}$ Under the DMA, obligations for Gatekeepers do not concern undertaking's entire business activity but only the provision of specific services, and the Gatekeeper position must rely to precisely those, see Rupprecht Podszun, Philipp Bongartz, and Sarah Langenstein, The Digital Markets Act: Moving from Competition Law to Regulation for Large Gatekeepers, 10 Journal of European Consumer and Market Law 2021, 60, 63.

${ }^{27}$ As the consequence is that such services will not be provided by Gatekeepers at all, no case exists for the DMA to apply. Therefore, the DGA must stipulate such a prohibition, not the DMA.
} 
intermediaries and, consequently, more vivid competition on the markets for data intermediation services.

15. The DMA mandates, presumes or prohibits data transfers in various contexts. The recognition that such data-related rights and obligations under the DMA could foster the role of DGA data intermediaries ${ }^{28}$ should not remain a diagnosis but call for a more active and integrated regulatory approach whereby the DMA systematically envisages a significant role for (non-Gatekeeper) DGA data intermediaries.

15.1. The DMA contains various obligations for Gatekeepers to transfer data, especially Art. 5(g), Art. 6(1)(g), (h), (i), (j), Art. 13 DMA. Regarding such transfers data intermediaries (especially Data Intermediary Trustees) could provide technical infrastructure, organize data pooling and interoperability, as well as negotiate and implement FRAND transaction conditions. It seems likely that they could play a vital role in making FRAND work under the Package and that playing such a role could, vice versa, help them to succeed and gain acceptance in the market (cf. III.).

15.1.1. Where personal data is involved, data intermediaries could, also with the help of algorithmic (AI) tools, offer consent management and implement anonymization or differential privacy solutions. Especially for these contexts, as well as for portability transactions under Art. 6(1)(h) DMA, data intermediaries should develop into Data Intermediary Trustees. Art. 5(a) DMA, for instance, prohibits the combination of personal data from different sources absent end user choice and informed consent. While intermediaries can support the management of such end users' consents, ${ }^{29}$ doubts are warranted over whether this provision effectively reaches its goals and is sufficiently circumvention-proof. ${ }^{30}$ These concerns suggest going a step further and mandating Data Intermediary Trustees to rate, certify or label the data options offered by Gatekeepers, thus serving as "data guides" for consumers. ${ }^{31}$

15.1.2. These reflections also corroborate the claim that Gatekeepers ought to be prevented from offering data sharing services under Art. 9(1)(b) and (c) DGA: ${ }^{32}$ The current Art. 5(a) DMA is likely to incentivize Gatekeepers to set up such services themselves. So far, neither the DMA nor the DGA would prohibit them to do so, subject only to the obligation of neutrality and structural separation under Art. 11(1) DGA.

\footnotetext{
${ }^{28}$ Cf. Vezzoso (supra 7), 403.

29 ibid.

${ }^{30}$ Cf. Rupprecht Podszun, Should gatekeepers be allowed to combine data? - Ideas for Art. 5(a) of the draft Digital Markets Act (June 4, 2021), available at https://ssrn.com/abstract $=3860030$.

31 ibid, p. $11 \mathrm{ff}$.

${ }^{32} \mathrm{Cf}$. above 13.4 .
} 
15.1.3. If Gatekeepers materially and repeatedly violate limitations on the use of data they collect (such as Art. 6(1)(a) DMA: no use of competitors' data for own competitive advantage), Data Intermediary Trustees could police their conduct, e.g. by acting as primary data collectors which control data flows to and data use by Gatekeepers.

15.1.4. By performing the aforementioned functions, data intermediaries would likely evolve into innovation drivers, including in the area of complex, beneficial (and potentially thus certified) data processing algorithms. The legislator should even consider permitting to Data Intermediary Trustees processing prohibited to Gatekeepers, for instance the use of comprehensive data sets generated by various business platform users (Art. 6(1)(a) and (i) DMA). Society and economy could thus tap the innovation potential of combined data set analysis, while avoiding the risks - and the dynamically inefficient distrust - engendered by having powerful market players carry out such analysis in their own interest.

15.2. In light of the innovation and pro-competitive potential of data intermediaries, the regulator should actively further their involvement in data-related DMA transactions.

15.2.1. Considering the lack of regulatory experience and the early stage of data (intermediary) markets, it seems unwise to make broadscale involvement of data intermediaries mandatory.

15.2.2. However, the DMA should take a nudging approach by obliging Gatekeepers to provide data recipients and data subjects with the option to conclude their DMA transaction via intermediaries. In appropriate settings, this option could become the default, e.g. regarding $\mathrm{B} 2 \mathrm{C}$ transactions or $\mathrm{B} 2 \mathrm{~B}$ transactions with a strong impact on the interests of individual data subjects.

15.2.3. The EU Commission has discretion to impose concrete measures by Gatekeepers under Art. 7(2) DMA and to adopt implementing acts regarding Art. 6(1) lit. (h), (i) and (j) DMA (cf. 4.1. and 4.2.). It should use these powers to involve data intermediaries and the DMA should explicitly mention the possibility of mandating data transfer via an independent intermediary as a conditions/measure under Art. 7 and Art. 36 DMA. A similar approach should apply to Art. 5 DMA, including the data-related obligation of Art. 5(g) (on the extension of Art. 7 and Art. 36 to Art. 5 DMA, cf. 4.).

15.3. To allow for such a role of data intermediaries, however, also the DGA must be brought in better sync with related elements of the legal framework.

15.3.1. The DMA and other upcoming legislation should explicitly reference to the DGA where appropriate. 
15.3.2. The legislator ought urgently to extend the scope of the DGA's data intermediary provisions to mandatory data transfers. ${ }^{33}$ Presently, the DGA applies, without good reasons, only to data sharing based on voluntary agreements (Art. 2(7) DGA), whereas data sharing on basis of the DMA is obligatory.

15.3.3. For a combined application with legislation that was enacted previously or fails to reference it, the DGA should contain a "docking clause". Such a clause could, for instance, permit an active role of data intermediaries in sectoral data sharing obligations under Art. 20 GDPR.

\section{Towards a More Comprehensive Regulatory Framework - the} Role of the Envisaged "Data Act"

16. In the development of a regulatory framework for the digital economy, the Acts of the Package constitute important and far-reaching steps, but they are not comprehensive enough. This finding is certainly no claim for a "total regulation" of digital markets. Where the legislature subjects only some of the interrelated elements of a market system to regulation, though, while the need for regulating the other elements remains unassessed, resulting incoherencies may threaten the very goals of the regulation. We identify the following, non-exclusive aspects to be considered for additional regulatory measures:

16.1. Very large players holding key positions in digital markets are a suitable primary object for regulation, both because they have the power to shape the digital environment and because their economic strength can sustain avoidable burdens imposed by a regulation that is still in an exploratory, none to perfect phase. However, there are many more companies than GAFAM whose conduct has a strong impact on the digital economy. Even if they are not (yet) dominant in their respective markets, network and tipping effects may swiftly increase their market power and they may enjoy superior bargaining power visà-vis large groups of customers and business partners well below the dominance threshold. Arguably, the present legal framework is suboptimal regarding not only the very large but also a broader range of digital players. Having gained experience from the regulation presently undertaken, European law makers should expand it into a regulatory framework which is more comprehensive, encompassing i.a. companies with market power below dominance (potentially according to a context-specific interpretation of the "relative" market power concept embedded in certain EU Member States' laws) ${ }^{34}$. Corresponding to its broader scope, such a more generic regulatory framework ought not to impose obligations of compliance, and of

${ }^{33}$ Cf. also Richter (supra 23), 666.

${ }^{34}$ For an overview on relative market power in EU Member State competition law, cf. Eckart Bueren, Anna Wolf-Posch, and Peter Georg Picht, Relative Marktmacht im D-A-CH-Rechtsraum, 19 Zeitschrift für Wettbewerbsrecht 2021, 173. 
policing the compliance of others, as far-reaching as the obligations for Gatekeepers. It should, however, pay particular attention to market tipping, oligopolization and path-dependency risks resulting from the data-related activities of non-Gatekeeper companies.

16.2. More fine-tuning is needed to establish a differentiated (including sector-specificity), dynamically efficient grid of rules for personal and non-personal data.

16.2.1. In substance, the legislator has to reconcile two goals: safeguarding the fundamental elements of data protection and privacy while fostering innovation through data access and processing. The lack of said grid of rules risks to harm both of these goals. This is particularly evident for "mixed" data portfolios ${ }^{35}$ not clearly consisting of non-personal data only, for settings in which optimal anonymization of personal data seems unclear or unavailable, and for cross-border transactions engaging the data protection rules of various jurisdictions.

16.2.2. The legislator could address such scenarios by pursuing a two-tiered approach: First, and not least from a transaction cost perspective, non-personal data rules should build on established, though adapted, regulatory mechanisms of data protection regulation. Indeed, the DGA illustrates the trend that regulation for nonpersonal data approximates, to some extent, familiar data protection governance schemes. ${ }^{36}$ Second, existing data protection rules should be revised to provide more granularity, flexibility and legal certainty, taking account of practical realities and the importance of increasing dynamic efficiency in data markets. Safe harbor rules for transactions over mixed data portfolios which display a reasonable level of anonymization present an important object for such a two-tiered approach.

16.3. The draft Acts of the Package largely turn a blind eye to datarelated intellectual property rights (IPR). ${ }^{37}$ This is flawed as, for instance, part of the data impacted by the Package will be subject to database, know-how/trade secret or other IPR.

16.3.1. So far, the Package does not sufficiently address an appropriate balance between the protection of such entitlements and - where necessary - the usability of the data they extend to. An important setting for which such a balance must be struck is the

\footnotetext{
${ }^{35}$ See also criticism regarding DGA of Graef/Gellert (supra 25), p. 5.

${ }^{36}$ Cf. Gerald Spindler, Schritte zur europaweiten Datenwirtschaft - der Vorschlag einer Verordnung zur europäischen Data Governance, Computer und Recht 2021, 98 (104).

${ }^{37}$ See e.g. Recital 12, Art. 5(7) DGA, Recital 41 DSA. See also Matthias Leistner, The Commission's vision for Europe's Digital Future: Proposals for the Data Governance Act, the Digital Markets Act and the Digital Services Act - A critical primer (February 23, 2021), available at https://ssrn.com/abstract=3789041, p. 5, stating that "[t]he devil will be in the details of practical implementation and coordination with IP and data law".
} 
mandatory, potentially FRAND-based, access to content protected by rights under the Database Directive (cf. 17.6.).

16.3.2. Claims resulting from the infringement of intellectual property rights should be moderated, for instance by merely granting limited financial compensation where such infringement was difficult to avoid in performing obligations (e.g. the fight against "illegal content", Art. 14, 17, 20 DSA) or encouraged actions under the Acts of the Package.

16.3.3. Data processing by, and data output of, systems of "artificial intelligence" arguably require more specific attention as well.

16.3.4. The Commission aims to address IPRs in the envisaged Data Act (cf. 17.) but it seems doubtful whether the Data Act will manage to single-handedly cover all IPR implications of the Package regulation. This necessitates a systematic analysis of these implications, including the question of whether DMA, DGA and DSA should themselves, directly or by referencing supplementary legislation, address at least their core IPR ramifications.

16.4. As already remarked in other contributions, ${ }^{38}$ the Package's handling of state enforcement is suboptimal in many respects and it does not even try to address appropriate private enforcement. ${ }^{39}$

16.4.1. In the realm of data-related rights, obligations and transactions, enforcement mechanisms should take a shape both more comprehensive and keyed to this context.

16.4.2. As an instance for this moving away from a one-size-fits-all enforcement approach, data-related private enforcement could accentuate ex-ante conduct remedies, as an addition to ex-post damages, and encompass access to (including the compliance with portability standards) or information on data held by an entity; correction or erasure of data; the untangling of data sets unduly combined; (improvement of) anonymization; handling of data by a neutral trustee; assessment of and, where appropriate, modifications to the workings of data-processing algorithms; remuneration or the provision of security even prior to the definitive determination of damages or fair royalties; (preliminary) injunctions against the use of data. Especially private enforcement likely profits from an express,

\footnotetext{
${ }^{38}$ Cf. in detail Martin Eifert, Axel Metzger, Heike Schweitzer, Gerhard Wagner, Taming the Giants: The DMA/DSA Package, 58 Common Market Law Review 2021, 987 (1018 ff.); furthermore Podszun/Bongartz/Langenstein (supra 26), 66 f.; Cabral et al. (supra 4), p. $28 \mathrm{f}$.

${ }^{39}$ Cf. Giorgio Monti, The Digital Markets Act - Institutional Design and Suggestions for Improvement (February 22, 2021), TILEC Discussion Paper No. 2021-04, available at https://ssrn.com/abstract=3797730, p. 11 ff.; Peter Picht, Private Enforcement for the DSA/DGA/DMA Package: Competition Law Lessons and Beyond, Verfassungsblog (3 Sep 2021) https://verfassungsblog.de/power-dsa-dma09/; Leistner (supra 37), p. 7 ff.
} 
broad set of available remedies that reduces uncertainty for market participants pondering whether to take legal action.

16.4.3. A Multi-prong private enforcement, utilizing not only a combination of competition and tort law but, in a concerted manner, also contract, data protection and unfair competition law, seems particularly apt for a context in which relative, contractual relationships loom large and competitive effects on a macroeconomic scale can be hard to assess.

16.4.4. On the procedural level, agents (e.g. data intermediaries, data protection authorities) and procedures (e.g. audits, such as pursuant to Art. 28 DSA) established for data transactions should be employed for data-related enforcement as well.

17. The Commission should design its envisaged Data Act to become a key element in a comprehensive regulatory framework, addressing, inter alia, several of the points made in this Paper. For this venture, the Data Act must take into consideration the discourse on the presently submitted Package Acts and impact these Acts, through direct rules or indirectly as a blueprint. The more the Acts of the Package leave out, the greater and more extensive is the need for the Data Act to close the gaps (for IPR cf. already 16.3.). Undoubtedly, it is paramount for the Data Act to be closely interconnected with DMA, DSA and DGA, as the following examples underline:

17.1. The Data Act can specify portability requirements and generically include cloud computing services for the EU's digital regulation as a whole. The design of potential rules on cloud service portability $^{40}$ should account for the applicability of the DMA and the DGA to cloud services as well (cf. 14.2.).

17.2. The Data Act's approach to the use of privately held data by the public sector (B2G) can be informative for the role of data intermediaries under other Acts. In particular, effective and efficient B2G transactions may require (or be framed to require) data intermediaries. This provides an additional argument for extending the scope of the DGA to mandatory data transfer (cf. 15.3.2.)

17.3. The envisaged Data Act addresses the actual negotiating power in B2B data sharing settings, ${ }^{41}$ which can be seen as one step towards an extension of DMA-type regulation to market power below dominance (cf. 16.1.). In such settings, the legislator could mandate mutual data sharing under certain circumstances and to the extent this seems acceptable from a competition law perspective. This would prevent the data holder with stronger negotiating power from

\footnotetext{
${ }^{40}$ Cf. Inception impact assessment, Ares(2021)3527151, p. 3.

41 ibid, p. 2.
} 
unilaterally exploiting the weaker party's data. At the same time, this would allow for innovative uses of data on both sides.

17.4. The Data Act should make access restrictions and other procedural confidentiality safeguards established by the Know-How Directive available in proceedings under the Acts of the Package, so as to protect confidential data (including FRAND data license contracts) ${ }^{42}$ being the subject of such proceedings.

17.5. We welcome the planned re-examination of database protection in the frame of the Data Act. This revision should make the Database Directive - if it confirms its necessity at all - more flexible and take data access and dynamic competition considerations into account, thereby adapting the Directive to the technical and economic realities of the data-driven economy. ${ }^{43}$ Furthermore a revision needs to ensure that database rights do not hamper obligatory or desirable data transactions under the Package.

\footnotetext{
42 On confidentiality protection for FRAND license contracts in view of the KnowHow Directive, cf. Peter Georg Picht, Geheimnisschutz in SEP/FRAND-Verfahren, das GeschGehG und die Patentrechtsreform, 13 Zeitschrift für Geitsiges Eigentum 2021, 133.

${ }^{43}$ As a step into the right direction, the recent judgement of the CJEU in CV-Online Latvia (CJEU C-762/19 CV-Online Latvia (2021) EU:C:2021:434) requires courts in the future to strike a balance between interests of makers, users and competitors of databases for determining the legitimate scope of protection. However, details remain overly vague and the Commission should therefore take the review of the Database Directive as an occasion to re-conceptualize exclusive database rights accordingly.
} 